\title{
Behavior of Inflammatory Markers of Myocardial Injury in Cardiac Surgery. Laboratory Correlation with the Clinical Picture of Postpericardiotomy Syndrome
}

\author{
Ilmar Köhler, Paulo J. Saraiva, O rlando B.W ender, A lcides J. Zago
}

Porto Alegre, RS - Brazil

\begin{abstract}
Objective - To verify the association of serum markers of myocardial injury, such as troponin I, creatinine kinase, and creatinine kinase isoenzyme $M B$, and inflammatory markers, such as tumor necrosis factor alpha (TNF-alpha), $C$-reactive protein, and the erythrocyte sedimentation rate in the perioperative period of cardiac surgery, with the occurrence of possible postpericardiotomy syndrome.
\end{abstract}

Methods - This was a cohort study with 96 patients undergoing cardiac surgery assessed at the following 4 different time periods: the day before surgery (D0); the 3 rd postoperative day (D3); between the 7th and 10th postoperative days (D7-10); and the 30th postoperative day (D30). During each period, we evaluated demographic variables (sex and age), surgical variables (type and duration, extracorporeal circulation), and serum dosages of the markers of myocardial injury and inflammatory response.

Results - Of all patients, 12 (12.5\%) met the clinical criteria for a diagnosis of postpericardiotomy syndrome, and their mean age was 10.3 years lower than the age of the others $(P=0.02)$. The results of the serum markers for tissue injury and inflammatory response were not significantly different between the 2 assessed groups. No significant difference existed regarding either surgery duration or extracorporeal circulation.

Conclusion - The patients who met the clinical criteria for postpericardiotomy syndrome were significantly younger than the others were. Serum markers for tissue injury and inflammatory response were not different in the clinically affected group, and did not correlate with the different types and duration of surgery or with extracorporeal circulation.

Key words: cardiac surgery, inflammatory markers, injury markers, postpericardiotomy syndrome.

Hospital de Clínicas de Porto Alegre and Faculdade Farmácia/Bioquímica - UFRGS Mailing address: Ilmar Köhler - Rua Prof. Ivo Corseuil, 474 - 90690-410 - Porto Alegre, RS, Brazil - E-mail: i.kohler@terra.com.br
Postpericardiotomy syndrome, which begins between the first and the second postoperative week after cardiac surgery, is characterized by thoracic pain, fever, malaise, and pericardial or pleural rub, or both of these. It was first described in $1952^{1}$, spawning interest about its developmental aspects.

This syndrome was initially described in relation to valvar surgery, which was the most common surgery at that time. This connection with valvar surgery suggested the possibility of rheumatic fever reactivation ${ }^{2}$, with the possibility of an immunologic cause.

It was believed that perioperative trauma triggered this immunologic response through the dissemination of endogenous streptococci or other inflammatory agents ${ }^{2}$.

The recognition of an immune response and other forms of trauma called postcardiac injury ${ }^{2}$ as triggering mechanisms inspired research related to humoral and cellular immunologic responses. These initial studies using antibodies with low specificity, resulted in conflicting conclusions that decreased the interest in the investigation of this syndrome, after many studies published in the 1970s and 1980s.

With new techniques for serum marker determination, it is possible to test the different constituents released by the loss of integrity of the myocardial cell, which created the possibility of finding a gold standard for laboratory diagnosis of the syndrome and a possible reference for its clinical evolvement.

Cytokines, secreted by T-helper lymphocytes in response to antigenic stimulus, regulate the main biologic process, such as the activation of cell linage, inflammation, and in the restoration of injured tissues. Proinflammatory cytokines release TNF-alpha, and interleukins IL-6 and IL-8 may occur as a response to systemic inflammatory response syndrome, in the postoperative period after cardiac surgery ${ }^{3}$.

TNF-alpha is a cytokine mediator of natural immunity, produced primarily by macrophages but also by lymphocytes and natural killer cells (NK cells). The heart also produces TNF-alpha, synthesized both by myocardial macrophages and by cardiac myocites ${ }^{4}$. 
TNF-alpha may contribute to postischemic myocardial dysfunction through direct depression of contractility and myocyte apoptosis, called postpump inflammatory syndrome. This depression of myocardial function seems to be induced by both nitric-oxide dependent and nitric-oxide independent mechanisms.

Additionally, the role of inflammation in acute ischemic syndromes and possibly in other forms of myocardial injury was reinforced by the dosages of C-reactive protein. Creactive protein, which is a marker of inflammation, may be elevated in unstable angina and acute myocardial infarction, reflecting the inflammatory pathogenesis of these events. We can infer that this pattern may occur in other forms of tissue injury, which may facilitate the understanding of the inflammatory-immunologic mediation of postcardiotomy syndrome.

Because of the publications already mentioned, the evaluation of C-reactive protein has been recommended as an important marker of inflammatory response to cardiac injury. However, its participation as an independent risk factor for severe events (death or myocardial infarction) in this group of patients is conflicting ${ }^{5}$. It was included in the present study because we believe that the physiopathogenesis of postpericardiotomy syndrome is due to perimyocarditis injury, and because $\mathrm{C}$-reactive protein has not been tested in this type of event.

Creatinine kinase (CK) and its isoenzyme MB (CK-MB) were the first markers of injury described in the 1960s in myocardial infarction ${ }^{6}$. It has been demonstrated that creatinine kinase isoenzyme MB had greater sensitivity and specificity, and therefore it became the gold standard in the evaluation of ischemic injury.

Both creatinine kinase and creatinine kinase isoenzyme $\mathrm{MB}$ can increase due to muscular injury in the postoperative period of cardiac surgery; however, usually creatinine kinase isoenzyme MB does not increase to more than 5-10\% of the total creatinine kinase ${ }^{7}$.

In cardiac surgeries, 2 possible causes of ischemic injury exist: (1) during aortic clamping, which can occur during any type of surgery and (2) due to perioperative myocardial infarction in myocardial revascularization surgeries $^{8}$. Troponin I (cTnI) stands out as a new standard for the diagnosis of myocardial infarction and for the detection of mild myocardial injuries ${ }^{9}$.

Clinical manifestations of postpericardiotomy syndrome are extremely variable ${ }^{10}$. They can start around the 7 th to 8 th postoperative day, usually between the $2 \mathrm{nd}$ and $3 \mathrm{rd}$ week. Sometimes, they may occur even later, between the 5 th and 10th month ${ }^{11}$.

Urschel et al ${ }^{12}$ described the incidence of signs and symptoms in 45 patients with the syndrome. They observed the occurrence of fever in all cases, the increase in thoracic pain ( $95 \%$ ), of leukocytosis ( $84 \%$ ), the increase in the erythrocyte sedimentation rate - ESR - $(80 \%)$, malaise and weakness (69\%), and pericardial or pleural effusion (67\%).

The objective of the present study was to assess the pattern of serum markers of injury [troponin I (cTnI), creatinine kinase (CK), and creatinine kinase isoenzyme MB (CK-
MB)] and inflammatory markers, erythrocyte sedimentation rate (ESR), tumor necrosis factor alpha (TNF-alpha), and $\mathrm{C}$-reactive protein in the perioperative period of cardiac surgery, correlating its serum increase with the clinical picture of postpericardiotomy syndrome.

\section{Methods}

Because no parameters existed for calculating the size of the sample, we included in the study 114 adult patients undergoing cardiac surgery at the Hospital de Clínicas de Porto Alegre (HCPA), from March 06, 1998 to September 29, 1998, after informed written consent was signed. Of all patients, 7 were excluded because they had intra- or postoperative complications, or both, as predicted in the exclusion criteria, 9 were excluded because of technical problems with their blood sample during collection or storage, and 2 were excluded because they did not return to the ambulatory clinic 30 days after the procedure. We assessed the data of 96 patients that fulfilled all the necessary requirements.

The study design was from a contemporary cohort. All patients included were evaluated during the following 4 phases of the study: the day before surgery (D0), the 3rd postoperative day (D3), after hospital discharge, between the 7th and 10th postoperative days (D7-10), and the 30th postoperative day (D30), when patients returned for the ambulatory appointment especially designed for the present study.

We excluded patients who, during perioperative follow-up, had situations previously defined and approved as exclusion criteria ie, intraoperative myocardial infarction, septicemia, mediastinitis, adult respiratory distress syndrome (ARDS), and allergic reactions to drugs or transfusional incompatibility.

In each of the 4 phases of evaluation, patients underwent a previously defined protocol approved by the UFRGS - HCPA Ethical Committee in which the general clinical parameters and especially the study variables were assessed. On these occasions, blood samples were collected and electrocardiography was performed. Blood was collected in 2 tubes, one was sent to the central HCPA laboratory for routine examinations, and the other was centrifuged to be immediately stored at $-70^{\circ} \mathrm{C}$.

Electrocardiogram and routine examinations in the postoperative period of cardiac surgery aimed at detecting the occurrence of perioperative myocardial infarction.

After hospital discharge between the 7th and 10th postoperative days, the patient was asked to return on the 30 th postoperative day to undergo a procedure identical to that performed during the 3 previous phases.

Blood samples were sent to the Immunologic Laboratory of the School of Pharmacy for serum marker determination. Both clinical investigators and those who performed laboratory analysis were unaware of each other's results.

In the next phase, all the clinical information were tabulated and added to the laboratory results and then both were sent for statistical analysis. 
Laboratory analysis included determination of serum creatinine kinase through immune inhibition with the CKNAC Biodiagnostic BD 1010 kit, with a maximum expected value of $165 \mathrm{U} / 1$, and of isoenzyme $\mathrm{MB}$, also dosed through immune inhibition with the isoenzyme MB-NAC Biodiagnostic BD $1050 \mathrm{kit}$, with a maximum normality value of $30 \mathrm{U} / 1$. Troponin I was determined through enzyme immunoassay, by using the Opus Plus kit from Behring Diagnostic, with a minimal concentration of $0.5 \mathrm{ng} / \mathrm{mL}$.

Among the inflammatory markers, the erythrocyte sedimentation rate was determined by the automated Vesmatic 20 method, and the result was perfectly correlated with those obtained by using Vestegreen's reference method and using $40 \mathrm{~mm}$ in the 1 st hour as the normal expected value. C-reactive protein was analyzed through turbidimetry, using the Turbiquant $\mathrm{C}$-reactive protein method from Behring Diagnostic, with a normal expected value of $0.5 \mathrm{mg} /$ dL. Finally, tumor necrosis factor-alpha was assessed by using Quantikine R \& D Systems with $15 \mathrm{pg} / \mathrm{mL}$ immunoassay sensitivity values.

Because no parameters have been established for the definitive diagnosis of postpericardiotomy syndrome, and based on the recommendation of Maisch et al ${ }^{13}$, for this study, we have adjusted the signs and symptoms described by Urschel et al ${ }^{12}$.

Within this protocol, we classified patients with possible symptoms/signs of postpericardiotomy as those who had the following after the 7th postoperative day: a) initial or in creased thoracic pain, b) malaise/weakness, fever, or all of these, and c) the presence of pericardial or pleuropericardial rub.

Initially, frequency tables were created for all the variables in the database. Next, we calculated mean \pm standard deviation for the quantitative variables and the percentage for qualitative variables. When asymmetry in quantitative data occurred, we determined the interquartile range (difference between the 75 th percentile and the 25 th percentile). Statistical significance was determined by using the Student $t$ test for independent samples and, when asymmetry occurred we used the Mann-Whitney U test ${ }^{14}$. In the comparison of qualitative variables, the chi-square test was used. The significance level adopted was $\alpha=0.05^{15}$. Data analysis was performed with the help of SPSS software version 10.0, Epi-Info version 6.0, and PEPI version 3.0.

\section{Results}

Of the 96 patients assessed in the study, 63 (65.6\%) were men, and 33 (34.4\%) were women; the mean age was $56.3 \pm 14.9$, (between 14 and 83 ) years old.

Regarding the surgical procedure, most patients $(54.1 \%)$ underwent myocardial revascularization surgery, $38.6 \%$ underwent valvar surgeries, and $7.3 \%$ underwent congenital heart surgeries.

According to the proposed clinical classification, $87.5 \%$ of the patients did not have clinical evidence of postpericardiotomy syndrome (non-postpericardiotomy syndrome group), and $12.5 \%$ meet all the criteria for a definite clinical diagnosis (postpericardiotomy syndrome group).
Table I presents differences between the affected and unaffected groups regarding age and sex.

The group that developed clinical postpericardiotomy syndrome was significantly younger $(\mathrm{P}=0.024)$. No significant difference existed between the groups regarding sex.

As we can see in table II, congenital surgeries were performed more frequently in the postpericardiotomy syndrome group, and in the group without postpericardiotomy syndrome, mitral valve surgery was performed more frequently; however, this finding was not statistically significance $(\mathrm{P}=0.11)$.

Surgical time was slightly greater in the unaffected group $(\mathrm{P}=0.07)$, as was the duration of extracorporeal circulation $(\mathrm{P}=0.32)$.

Regarding laboratory evaluation of the markers of myocardial injury, no significant difference occurred between the 2 groups measured in the 4 periods of the study (tab. III).

Troponin I was increased in the 2 groups, in all stages assessed, and no statistically significant difference was established.

Creatinine kinase was above normal in $53 \%$ of the cases in the 3 rd postoperative day, correlating with a greater duration of extracorporeal circulation; however, it was not associated with the outcome of postpericardiotomy syndrome. In the other 3 periods of evaluation, creatinine kinase was increased in a small number of cases, without statistical significance.

Likewise, creatinine kinase isoenzyme MB was increased in $13 \%$ of the cases on the 3 rd postoperative day and was more intensively associated with the greater duration of extracorporeal circulation and of intraoperative trauma. It

\begin{tabular}{|c|c|c|c|}
\hline \multicolumn{4}{|c|}{$\begin{array}{c}\text { Table I - Comparison between the } 2 \text { groups regarding demographic } \\
\text { variables }\end{array}$} \\
\hline Variables & $\begin{array}{c}\text { Group PPS } \\
(\mathrm{n}=12)\end{array}$ & $\begin{array}{l}\text { Group Non-PPS } \\
(\mathrm{n}=84)\end{array}$ & $P$ \\
\hline Age years & $47.3 \pm 19.6$ & $57.6 \pm 13.7$ & 0.02 \\
\hline Male sex & $9(75)$ & $54(64.3)$ & 0.68 \\
\hline
\end{tabular}

\begin{tabular}{|lccc|}
\hline \multicolumn{4}{|c|}{ Table II - Comparison between groups regarding surgical variables } \\
\hline Variables & $\begin{array}{c}\text { Groups PPS } \\
(\mathrm{n}=12)\end{array}$ & $\begin{array}{c}\text { Group Non-PPS } \\
(\mathrm{n}=84)\end{array}$ & $P$ \\
\hline Types of surgery & & & \\
Mitral valvar & $1(8.3)$ & $17(20.2)$ & \\
Aortic valvar & $3(25)$ & $15(17.9)$ & 0.11 \\
Myocardial rev. & $5(41.7)$ & $47(56)$ & \\
Congenital & $3(25)$ & $4(4.8)$ & \\
Mitro-aortic valvar & 0 & $1(1.2)$ & \\
Duration of surgery & $150(72-222)$ & $210(125-300)$ & 0.07 \\
Duration of ECC min & $40(38-57)$ & $49(29-77)$ & 0.32 \\
\hline Data are presented as frequency (\%) and median (interquartile amplitude) \\
P25 - P75). PPS- postpericardiotomy syndrome, ECC- extracorporeal \\
circulation.
\end{tabular}




\begin{tabular}{|c|c|c|c|c|}
\hline \multicolumn{5}{|c|}{$\begin{array}{c}\text { Table III - Comparison between the results of myocardial injury } \\
\text { markers in the } 2 \text { groups of patients according to the periods of } \\
\text { evaluation }\end{array}$} \\
\hline Markers & $\begin{array}{c}\text { Days of } \\
\text { Evaluation }\end{array}$ & $\begin{array}{l}\text { Group PPS } \\
(\mathrm{n}=12)\end{array}$ & $\begin{array}{c}\text { Group Non-PPS } \\
(\mathrm{n}=84)\end{array}$ & $\mathrm{P}$ \\
\hline \multirow[t]{4}{*}{$\mathrm{cTnI}$ ng/ml } & 0 & $4.2(2.3-14.8)$ & $7.2(1.1-20)$ & 0.95 \\
\hline & 3 & $5.7(2.6-15.7)$ & $3.6(1.5-10.9)$ & 0.24 \\
\hline & $7-10$ & $6.1(1.4-9.9)$ & $4.0(1.3-8.6)$ & 0.76 \\
\hline & 30 & $5.9(4.6-9.8)$ & $3.0(0.5-8.7)$ & 0.14 \\
\hline \multirow[t]{4}{*}{ CPK U/1 } & 0 & $41(29-45)$ & $40(21-62)$ & 0.75 \\
\hline & 3 & $190(46-316)$ & $173(80-314)$ & 0.93 \\
\hline & $7-10$ & $20(18-44)$ & $46(26-80)$ & 0.10 \\
\hline & 30 & $39(29-61)$ & $38(22-71)$ & 0.74 \\
\hline \multirow[t]{4}{*}{ CK-MB U/1 } & 0 & $1(0-1)$ & $1(1-5)$ & 0.24 \\
\hline & 3 & $6(2-15)$ & $7(1-20)$ & 0.83 \\
\hline & $7-10$ & $1(1-4)$ & $3(1-6)$ & 0.22 \\
\hline & 30 & $2(2-4)$ & $3(1-7)$ & 0.72 \\
\hline \multicolumn{5}{|c|}{$\begin{array}{l}\text { Data are presented as median (interquartile amplitude: P25- P75). PPS- } \\
\text { postpericardiotomy syndrome; cTnI- troponin I; CPK- creatinine kinase; } \\
\text { CK-MB creatinine kinase isoenzyme MB. }\end{array}$} \\
\hline
\end{tabular}

was also not associated with the outcome of symptoms/ signs of postpericardiotomy syndrome.

Inflammatory markers, just as myocardial injury markers, did not have a statistically significant difference, and are detailed in table IV in the different stages of comparison.

C-reactive protein, increased in most cases especially on the $3 \mathrm{rd}$ and 7 th postoperative days possibly due to the surgical procedure, did not facilitate identifying the group affected by postpericardiotomy syndrome, even when assessing using different cutoff points.

TNF $\alpha$ did not have results of statistical relevance. A small number of patients had values above normal even on the 3 rd postoperative day, possibly because of the 72 -hourinterval, when the predicted alterations, induced by the surgical procedure should return to normal levels. Also the erythrocyte sedimentation rate, which is a known marker of low specificity, was not significantly associated with postpericardiotomy syndrome. Between the 3rd and the 7th

\begin{tabular}{|c|c|c|c|c|}
\hline \multicolumn{5}{|c|}{$\begin{array}{c}\text { Table IV - Comparison of the results of inflammatory markers in the } \\
2 \text { groups of patients according to the periods of evaluation }\end{array}$} \\
\hline Markers & $\begin{array}{l}\text { Evaluation } \\
\text { days }\end{array}$ & $\begin{array}{l}\text { Group PPS } \\
\quad(\mathrm{n}=12)\end{array}$ & $\begin{array}{l}\text { Group Non-PPS } \\
\quad(\mathrm{n}=84)\end{array}$ & $\mathrm{P}$ \\
\hline \multirow[t]{4}{*}{$\mathrm{CPR} \mathrm{mg} / \mathrm{dl}$} & 0 & $2.3(0.5-12.5)$ & $1.2(0.5-7.3)$ & 0.44 \\
\hline & 3 & $9.4(7.0-13.4)$ & $13.7(8.0-25.1)$ & 0.09 \\
\hline & $7-10$ & $5.2(1.0-6.9)$ & $5.4(2.8-10.9)$ & 0.21 \\
\hline & 30 & $0.5(0.5-1.4)$ & $0.7(0.5-2.4)$ & 0.29 \\
\hline \multirow[t]{4}{*}{$\mathrm{TNF} \alpha \mathrm{pg} / \mathrm{ml}$} & 0 & $2.9(1.0-4.5)$ & $1.4(1.0-4.2)$ & 0.58 \\
\hline & 3 & $2.3(0.7-5.5)$ & $1.2(1.0-5.1)$ & 0.76 \\
\hline & $7-10$ & $3.4(0.6-6.3)$ & $1.6(1.0-4.8)$ & 0.94 \\
\hline & 30 & $4.2(1.2-6.5)$ & $1.3(1.0-4.3)$ & 0.08 \\
\hline \multirow[t]{4}{*}{ ESR $\mathrm{mm} / 1^{\text {ath }}$} & 0 & $15(5-33)$ & $29(13-44)$ & 0.15 \\
\hline & 3 & $83(73-107)$ & $82(60-99)$ & 0.65 \\
\hline & $7-10$ & $83(64-105)$ & $92(59-104)$ & 0.84 \\
\hline & 30 & $44(17-53)$ & $40(24-73)$ & 0.41 \\
\hline \multicolumn{5}{|c|}{$\begin{array}{l}\text { Data are presented as median (interquartile amplitude) P25 - P75). PPS- } \\
\text { postpericardiotomy syndrome; CPR- C-reactive protein; TNF } \alpha \text { - alpha } \\
\text { tumoral necrosis factor; ESR- erythrocyte sedimentation rate. }\end{array}$} \\
\hline
\end{tabular}

postoperative day, the number of patients with an erythrocyte sedimentation rate above $40 \mathrm{~mm}$ fluctuated around $90 \%$ and did not allow greater discrimination between the 2 groups.

\section{Discussion}

Postpericardiotomy syndrome has always been a challenge for those who take care of the postoperative period of cardiac surgery. When clinical features suggest its onset, antiinflammatory medication is administered, and, in many cases, the symptoms disappear without a clearly established diagnosis.

We were aware of the difficulties we would face in our study, because no standard for its diagnosis exists.

Of the results of demographic variables, age was lower in the group that developed postpericardiotomy syndrome. This finding is possibly related to a more reactive immunologic response in the younger group, already described ${ }^{16}$. Due to the sex, no differences existed.

Surgery and extracorporeal circulation duration, in contrast with the data from Maisch ${ }^{17}$ was not associated with the event, which may be justified by the development of greater intraoperative myocardial protection techniques, including cardioplegia and of new anesthetics.

The longer duration of aortic clamping was not related to the onset of postpericardiotomy syndrome, which may suggest the occurrence of another factor, with or without an association with transoperative trauma. The literature frequently mentions viral participation ${ }^{18}$ as a factor, especially in children ${ }^{19}$.

Much speculation exists about the role of inflammatory activity induced by acutely or chronically infectious agents, in the establishment of ischemic syndromes. Physiopathologic mechanisms are not totally clear ${ }^{20}$ and, theoretically they may occur in other forms of myocardial injury. We have to take into account that this infectious-inflammatory reaction may occur together with surgical trauma, justifying the inconstant pattern of surgical injury.

According to several authors ${ }^{21-23}$, TNF-alpha and interleukins correlate their responses with the duration of extracorporeal circulation, and its production would depend on ischemia-reperfusion, leading to acute and reversible ventricular dysfunction, a few hours after the end of extracorporeal circulation ${ }^{24}$.

In none of the periods of the study did the TNF-alpha demonstrate a correlation with the assessed surgical variables. It is known that its elevation occurs early after the procedure and lasts for 24 to 48 hours. For this reason, its dosage on the 3 rd postoperative day did not demonstrate the peak reached. The TNF-alpha could not detect the immune inflammatory response that occurs in the late stage of the postoperative period in individuals affected by postpericardiotomy syndrome, although it was still increased on the $3 \mathrm{rd}$ and 7 th postoperative days in a small number of cases, because of the early inflammatory response to intraoperative trauma. 
C-reactive protein values were increased in a great number of patients, especially between periods D3 and D710 , when it was not identifying the possibility of the onset of pericardiotomy syndrome because of the intense response to surgical trauma. Apparently, its response to operative trauma was so intense that it was not possible to recognize discreet differences between the 2 analyzed groups.

Troponin I, which directly assesses myocardial damage, especially when the cutoff value used is above the normal level, was determined a few times with the cutoff point at the limit of its normality $(<0.5 \mathrm{ng} / \mathrm{mL})^{25,26}$. In most publications, it was dichotomized with values ranging from 1.5 to $5.0 \mathrm{ng} / \mathrm{mL}^{27-31}$. In the present study, we used cutoff points in different percentiles; however, this did not change its pattern in either group.

The proposal to diagnosis postpericardiotomy syndrome based on clinical information may be a limiting factor of the study, due to the lack of standardization for the clinical outcome analyzed. This strategy was also used by Maisch et al ${ }^{13}$ whose standardization included only 3 clinical and laboratory variables.

The frequency of surgeries performed followed an unusual distribution, with a great number of valvar surgeries, responsible for almost $40 \%$ of all procedures. Myocardial revascularization was performed less frequently than reported in the literature, producing a peculiar characteristic in this study.

The values of $C$-reactive proteins were increased in a great number of cases, especially between periods $\mathrm{D} 3$ and D7-10. Apparently, its response to operative trauma was so intense that it was not possible to recognize discreet responses between the levels of response of the 2 analyzed groups, which may have been possible if its dosage had been administered by nephelometry.

Likewise, TNF-alpha assessed by using Quantikine HS (high sensitive) may perform better in discriminating between the 2 groups after the 3 rd postoperative day.

In conclusion, postpericardiotomy syndrome in the studied sample of adults included according to the inclusion criteria of the study occurred in $12.5 \%$ of the cases, and those affected were significantly younger than those not affected. The pattern of serum markers of myocardial injury and inflammatory response were not significantly different in the groups assessed. No significant difference existed between the 2 groups regarding the type of surgery and the duration of surgery and of extracorporeal circulation.

\section{Acknowledgments}

To Drs. Fabiano Ritter, Malba I. Zanella, Susan Brandão, Aline Z. Friedrichs, Marcelo Pimentel, Andreia S. Nunes, Anelise D. Wallau, and Larissa P.Centeno for help in the clinical evaluations and in the collection of data. To the biochemists André L. Souza, Clóvis Schäffer, and to the biologist Claudia Garcia for technical and laboratory support.

\section{References}

1. Spodick DH. Historical Cornestones in Pericardial Disease. In: Seferovic PM, Spodick DH and Maisch B. (eds): Pericardiology. $1^{\text {st }}$ edition, Belgrado: Ed. Science, 2000

2. Köhler, I. Síndrome pós-pericardiotomia. Quatro décadas de dúvida etiológica. Arq Bras Cardiol 1992; 60: 197-202.

3. Wan S, LeClerc JL, Vincent JR. Cytokine responses to cardiopulmonary bypass: lessons learned from cardiac transplantation. Ann Thorac Surg, 1997; 63: 269-76.

4. MeldrumDR. Tumornecrosis factor in the heart. Am JPhysiol 1998; 274: R577-95.

5. Liuzzo G, Biasucci LM, Gallmore RJ, Grillo RL, Rebuzzi AG, Pepys MB, Maseri A. The prognostic value of C-reative protein and serum amyloid A protein in severe unstable angina. N Engl J Med 1994;331: 317-24.

6. Van der Veen KJ, Willbrands A. Isoenzymes of creatine phosphokinase in tissue extracts and in normal and pathological sera. Clin Chim Acta 1966; 13:312-6.

7. Christenson RH, Newby, LK, Ohman EM. Cardiac markers in the assessment of acute coronary syndromes. Md Med J 1997; (suppl)18-24.

8. Fransen EJ, Maessen JG, Hermens WT, Glatz JF. Demonstration of ischemia-reperfusion injury separate from postoperative infarction in coronary artery bypass graft patient. Ann Thorac Surg 1998;1: 48-53.

9. Wu AHB, Feng, YJ. Biochemical differences between cTnT and cTnI and their significance for diagnosis of acute coronary syndromes. Eur Heart J 1998; 19(Suppl N): N25-N29.

10. Gray RJ. Pericarditis. The early postoperative phase in the hospital. In: Gray RJ, Matlof JM eds:Medical Management of the Cardiac Surgical Patient. Baltimore: Williams \& Wikins, 1990; 233.

11. Kloster FE. Diagnosis and management of complications of prosthetic heart valves. Am J Cardiol 1975; 35: 872-85.

12. UrschelHC, Razzuk HC, RazzukMA, GardnerM. Coronary artery bypass occlusion secondary to postcardiotomy syndrome. Ann Thorac Surg, 1976; 22: 528-34.

13. Maisch B, Berg PA, Kochsiek K. Clinical significance of immunopathological findings in patients with post-pericardiotomy syndrome-I. Revelance of antibody pattern. Clin Exp Immunol 1969; 38: 189-97.
14. Kirkwood, BR. Essentials of Medical Statistics. $1^{\text {st }}$ edition London: Blackwell Science Ltd. 1988.

15. Altman, DG. Practical statistics for Medical Research, $1^{\text {st }}$ edition London: Chapman \& Hall, 1991.

16. Engle MA, Gay Jr, WA, McCabe J, et al. Pospericardiotomy syndrome in adults: Incidence, autoimmunity and virology. Circulation 1981; 64 (suppl II): II58-II60.

17. Maisch B. Zur sekundaren immunpathogenese kardialer erkrankungen, Fortschr Med 1984; 102: 516-20.

18. Drusin LM, Engle MA, Hagstrom JWC, Schwartz MS. The post-pericardiotomy syndrome: a six year epidemiologic study. N Engl J Med, 1965; 272: 597-602.

19. Engle MA, Zabriskie JB, Senterfit LB, Gay Jr, WA, O'Loughlin JE, Ehlers KH. Viral Illness and the postpericardiotomy syndrome-a prospective study in children. Circulation, 1980; 62: 1151-8.

20. Toss H, Gnarpe J, Gnarpe H, Siegbahn A, Lindahl B, Wallentin L. Increased fibrinogen levels are associated with persistent Chlamydia pneumoniae infection in unstable artery disease. Eur Heart J 1998; 19: 570-7.

21. Whitten CW, Hill GE, Ivy R, Greilich PE, Lipton JM. Does the duration of cardiopulmopnary bypass or aortic cross-clamp, in absence of blood and/or blood product administration, influence the IL-6 response to cardiac surgery. Anesth Analg 1998; 86: 28-33.

22. Karube N,Adachi R, Ichikawa Y, Kosuge T, Yamazaki I, Soma T. Measurement of cytokines levels by coronary sinus blood sampling during cardiac surgery with cardiopulmonary bypass. ASAIO J 1996; 42: M787-91.

23. Cain BS, Meldrum DR, Dinarello CA, Meng X, Banerjee A, Harken AH. Adenosine reduces cardiac TNF-alpha production and human myocardial injury following ischemia-reperfusion. J Surg Res 1998; 76: 117-23.

24. Savaris N. Perfil imunoinflamatório e dosagem de troponina I após cirurgia de revascularização miocárdica com circulação extracorpórea: implicações sobre a função ventricular esquerda-Dissertação de Mestrado. UFRGS, Porto Alegre, 1998.

25. Prellwitz W, Hafner G, Rupprecht HJ, Meyer J. Diagnostic and differential diagnostic value of troponins. Med Klin 1996; 91: 336-42.

26. Polanczyk CA, Lee TH, Cook EF, Walls R, Wybenga D, Printy Klein G, Ludwig 
L, Guldbrandsen G, Johnson PA. Cardiac troponin I as a predictor of major cardiac events in emergency department patients with acute chest pain. J Am Coll Cardiol 1998; 32: 8-14.

27. Christenson RH, Duh SH, Newby LK, et al. Cardiac troponin T and cardiac troponin I: relative values in short-term risk stratification of patients with acute coronary syndromes. GUSTO IIA Investigators. Clin Chem 1998; 44: 494-501.

28. Bonnefoy E, Filley S, Kirkorian G, Guidollet J, Roriz R, Robin J, Touboul P. Troponin I, troponin T or creatine kinase MB to detect perioperative myocardial damage after coronary artery bypass surgery. Chest 1998; 114: 482-6.
29. Pervaiz S, Anderson FP, Lohmann TP, et al. Comparative analysis of cardiac troponin I and creatine kinase-MB as markers of acute myocardial infarction. Clin Cardiol 1997; 20:269-71.

30. Mair J, Larue C, Mair P, Balogh D, Calzolari C, Puschendorf B. Use of cardiac troponin I to diagnose perioperative myocardial infarction in coronary artery bypass grafting. Clin Chem 1994; 40: 2066-70.

31. Alyanakian MA, Dehoux M, Chatel D, et al. Cardiac troponin I in diagnosis of perioperative myocardial infarction after cardiac surgery. J Cardiothorac Vasc Anesth 1998;12:288-94. 